\title{
Pseudotumoral Form of Neuroschistosomiasis: Report of Three Cases
}

\author{
Antonio S. Andrade Filho ${ }^{1,2,3}$, Aristidez C. Queiroz ${ }^{1}$, Antonio C.C. Freire ${ }^{2}$, Leonardo Conrado S. Lima ${ }^{2}$, Celso A.S. Filho ${ }^{2}$, Isolda \\ N. Amado ${ }^{2}$, Mittermeyer G. Reis ${ }^{3,4}$, Isis Fernandes Magalhães ${ }^{4}$ and Theomira M.A. Carmo ${ }^{4}$ \\ ${ }^{I}$ Service of Clinical Neurology, HUPES-UFBA; ${ }^{2}$ Foundation of Neurology and Neurosurgery/Brains Institute; ${ }^{3}$ School of Medicine and Public \\ Health/EMSP; ${ }^{4}$ Oswaldo Cruz Foundation; Salvador, BA, Brazil
}

\begin{abstract}
Central nervous system (CSN) involvement in schistosomiasis is an ectopic manifestation with a large variety of clinical forms, including pseudotumoral, which occurs in isolated cases and is rare. Three patients with epidemiological indications of this pathology were examined; the clinical picture included lower-back pain irradiating to lower limbs, associated with progressive flaccid paraparesis and sphincterial disturbances in cases in which the spinal chord was involved; while in cases with encephalitic impairment, headache, dizziness and cerebellar syndrome, characterized by dysarthria and right-side dysgraphia, were present. Magnetic resonance imaging (MRI) showed a growing process in all cases; cerebrospinal fluid (CSF) characteristics and biological markers were compatible with neuroschistosomiasis (NS). Biopsy of the lesions confirmed this diagnosis in one case. After specific treatment with schistosomicides and corticosteroids, clinical, radiological and laboratorial improvement was observed.

Key-Words: Neuroschistosomiasis, pseudotumoral form, neuropathology.
\end{abstract}

Schistosomiasis occupies second place in frequency among the parasitoses that affect man; it is only exceeded by malaria. Schistosomiasis affects about 200 million people throughout the world [1]; in Brazil, about 12 million people have this illness [2-4]. Due to its prevalence and high morbidity, it is among the most-important public-health problems in tropical and subtropical areas, where the socio-economical factor, which results in poor conditions of hygiene and housing, favors the dissemination process. There are five species that can infect man; but only Schistosoma mansoni is found in Brazil [5].

Schistosomiasis may present in an ectopic form, which manifests as a specific local reaction to the worm or to its egg outside the portocaval system. Mansonic neuroschistosomiasis (NS) may manifest clinically through meningomyeloradiculitis, myelitis, radiculitis, or as the pseudotumoral, cerebral or spinal forms. Its diagnosis is fundamentally based on epidemiological, clinical, laboratorial and image data [6,7].

Among the low percentage of cases of central-nervoussystem (CNS) involvement, meningomyeloradicular is the most common in Brazil, accounting for about $80 \%$. Neurological onset may be explained by two basic mechanisms, direct and indirect. In the former, the parasite inside the tissue is able to bring about a local inflammatory reaction, and most anti-bodies that are produced will act against the soluble antigens of the schistosoma. Neuroschistosomiasis takes place due to embolization of eggs that come from pulmonary arteriovenous "shunts", or through Batson's vertebral venous plexus. When they come through the latter, there is evidence that the increase in intra-abdominal pressure favors migration. In the second

Received on 10 February 2007; revised 21 July 2007.

Address for correspondence: Dr. Antonio Andrade Filho. Rua Deocleciano Barreto, 10/Barra. Zip code: 40140-110, Salvador-Bahia-Brazil. E.mail: andradeneuro@uol.com.br.

The Brazilian Journal of Infectious Diseases 2007;11(4):435-438. (C) 2007 by The Brazilian Journal of Infectious Diseases and Contexto Publishing. All rights reserved. mechanism, deposits of immune complexes in CNS areas are responsible for unleashing the inflammatory process [8-10].

Treatment of this nosological entity is done with vermicides (praziquantel and oxamniquine), when there is active disease, with corticotherapy (in an attempt to reduce the inflammatory pattern) and with symptomatic medicine.

\section{Case Reports}

Case 1

Patient 32 years of age, female, brown-skinned, biologist, born in and living in the city of Salvador, Bahia state, with progressive decreasing muscle strength in her lower limbs, associated with lumbar and lower-limb pain during the previous 10 days. She evolved to flaccid paraparesis, and lack of patelar and Achilles-tendon bilateral reflex, intestinal constipation and urine incontinence. Her motor score was 11 and the total score was 17 in the functional incapacity scale (HEC), resulting in a classification of moderate incapacity.

She underwent serology (immunofluorescence) and an intradermal reaction test for schistosomiasis, both with negative results; parasitological feces exams of three samples gave no evidence of parasites, and the Baerman exam was negative. The first CSF exam (February 5, 2003), collected 12 days after the initiation of symptoms, had a turbid aspect, global cytology was 300 cells $/ \mathrm{mm}^{3}$, with a distribution of $73 \%$ lymphocytes, $14 \%$ reticulomonocytes, $8 \%$ plasmocytes and $4 \%$ eosinophiles. Atypical cells were not found. Biochemistry showed glucose (48 $\mathrm{mg} / 100 \mathrm{~mL})$, chlorides $(709 \mathrm{mg} / 100 \mathrm{~mL})$ and TGO $(6.8 \mathrm{IU} / 100 \mathrm{~mL})$ at normal levels. But there was an increase in protein $(85 \mathrm{mg} / 100$ $\mathrm{mL}$ ), as well as increased lactic dehydrogenase (37.4 IU/L). Pandy's reaction was positive (++) and the hemoagglutination and immunofluorescence reactions for schistosomiasis were, respectively, negative and frankly positive. Electrophoresis of proteins showed an increase of the gamma-globulin fraction (20.7). Antibody analysis against the soluble egg antigen (SEA), in the CSF, using an enzyme-linked immunosorbent assay (ELISA) was positive. The MRI of the chest and lumbar column (February 5, 2003) done with "SpinEcho", "Turbo Spin Echo" and 
"Inversion Recovery" demonstrated alterations in the diffuse signal of the marrow, characterized by a discrete hypo-signal at T1 and a strong signal at T2, spreading from the transition between T9 and T10 vertebral bodies to the medullar cone, with a slight insufflation effect at this latter topography (Figure 1). The patient had initially received specific clinical treatment wit praziquantel and dexamethasone, which gave progressive clinical improvement.

The second CSF sample (February 24, 2003) had a slightlyturbid aspect, with a global cytology of 70 cells per cubic millimeter, and a distribution of $69 \%$ lymphocytes, $27 \%$ reticulomonocytes and 3\% plasmocytes. Atypical cells were not found. The biochemistry gave evidence of glucose $(80 \mathrm{mg} /$ $100 \mathrm{~mL})$, chlorides $(709 \mathrm{mg} / 100 \mathrm{~mL}), \mathrm{TGO}(6.8 \mathrm{IU} / 100 \mathrm{~mL})$ and lactic dehydrogenase (30.0 IU/L) at normal levels. However, an increase in proteins was found $(57 \mathrm{mg} / 100 \mathrm{~mL}$.) Pandy's reaction was positive and the hemagglutination and immunofluorescence reactions for schistosomiasis were negative. Protein electrophoresis demonstrated an increase in the gamma-globulin fraction (19.8\%).

The MRI of the chest and the lumbar column was repeated 22 days after the first one, revealing an area with absence of T12 vertebral body signs, and a discrete dilatation of the medullar channel (Figure 2). The control MRI was made three months after initiation of symptomatology; it showed total regression of the medullar picture (Figure 3).

The patient evolved with progressive clinical improvement, with total score 2 on HEC's scale of functional incapacity, resulting in a slight incapacity classification.

\section{Case 2}

Patient 32 years old, male, plastic artist, married, white, born in and from the city of Porto Alegre, Rio Grande do Sul state, with a history of muscle force reduction in his lower limbs during the previous 10 days; he had evident flaccid paraparesis and urine retention. In the first sample (July, 8,
1997), the CSF exam presented a limpid aspect and slightly xantochromical coloration, with cytology displaying $0.3 \%$ cells $/ \mathrm{mm}^{3}$, with a distribution of $70 \%$ lymphocytes and $30 \%$ reticulomonocytes. No atypical cells were found. Biochemistry displayed glucose and chlorides at normal levels $(57 \mathrm{mg} / 100$ $\mathrm{mL}$ and $709 \mathrm{mg} / 100 \mathrm{~mL}$, respectively) and increased protein levels, which went as high as $170 \mathrm{mg} / 100 \mathrm{~mL}$. Pandy's reaction was positive, as were the hemagglutination (1:4) and immunofluorescence reactions. Protein electrophoresis showed an increase in the gammaglobulin fraction, reaching 19\%. The CT and MRI exams gave evidence of an intramedullar expansive process; the latter had findings compatible with myelitis or an expansive neoplastic process (Figures 4 and 5).

Biopsy of the lesion confirmed the diagnosis of medullar mansonic schistosomiasis. The patient received specific treatment, initially with praziquantel, during three days, and then prednisone. He presented progressive improvement, and was able to walk again, with some difficulty. There was also some improvement of the CSF (May 25,1998), its aspect being limpid and colorless, with the cytology presenting 0 cells/ $\mathrm{mm}^{3}$. In the biochemical exams, glucose and chlorides were normal, while proteins were increased $(56 \mathrm{mg} / 100 \mathrm{~mL})$. Pandy's reaction was positive, as was immunofluorescence. However, the hemagglutination reaction was negative, and the gammaglobulin fraction was within a normal range $(4.1 \mathrm{mg} / \mathrm{dL})$.

\section{Case 3}

TBN, 13 years of age, male, student, dark skinned, born and residing in the city of Salvador, Bahia, with a history of headache and dizziness for four weeks. At the neurological exam, he presented dysgraphia on the right side, and dysarthria on the left. The CSF analysis showed five cells/ $\mathrm{mm}^{3}$, with $56 \%$ lymphocytes, $21 \%$ reticulomonocytes, $4 \%$ plasmocytes and 16\% eosinophils. Atypical cells were not found. Biochemistry showed glucose $(58 \mathrm{mg} / 100 \mathrm{~mL})$ at normal levels. The hemagglutination and immunofluorescence
Figure 1.

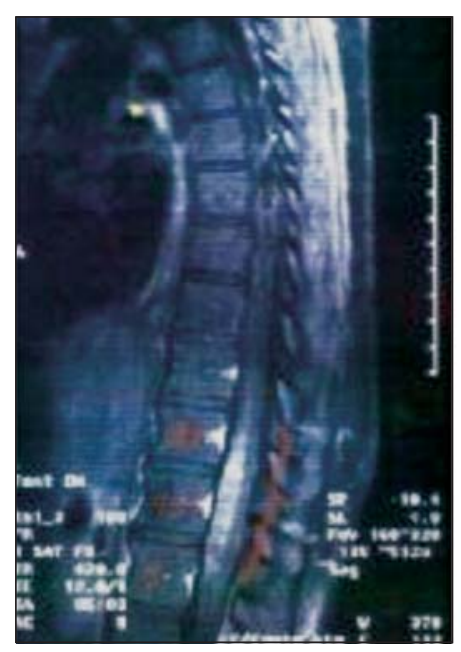

Figure 2.

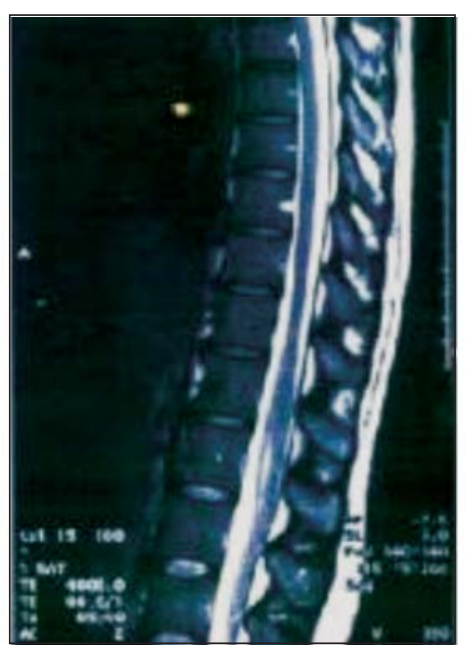

Figure 3.

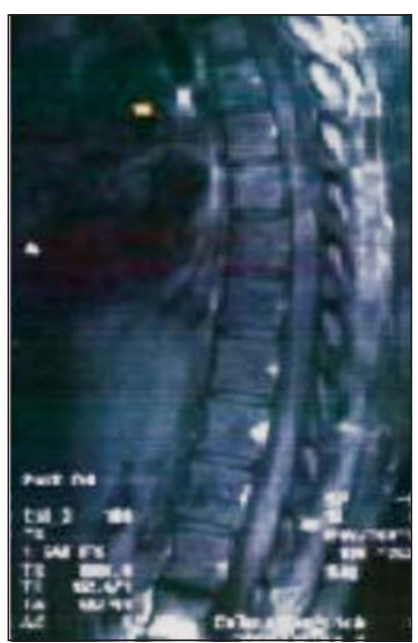

www.bjid.com.br 
Figure 4.

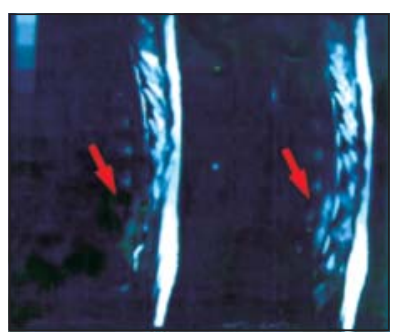

Figure 5.

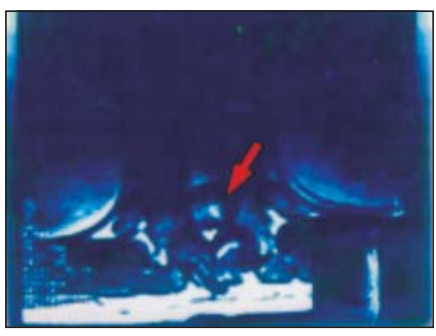

reactions for schistosomiasis were positive. Protein electrophoresis showed an increase in the gamma-globulin fraction (15.2\%). ELISA analysis of antibodies against SEA in the liquor proved positive. The MRI (June 12,1992) gave evidence of an expansive process in the encephalic trunk level (Figure 6). The patient received specific treatment with praziquantel and prednisone, with progressive clinical improvement. After two months of pharmacological treatment, the CSF exam was repeated; it showed 0 cells $/ \mathrm{mm}^{3}$. Biochemistry showed glucose $(77 \mathrm{mg} / 100 \mathrm{~mL})$ at normal levels. The hemagglutination and immunofluorescence reactions for schistosomiasis were negative. Protein electrophoresis showed normalization of the gamma-globulin fraction (7.5\%). The MRI was repeated four months later (October 22,1992), with evidence of improvement (Figure 7).

\section{Discussion}

We report two cases of patients who developed secondary compressive myelitis, associated with the pseudotumoral medullar form of mansonic schistosomiasis, and one case of encephalic compromise. CNS involvement, as with NS, may occur at any stage of the disease, including the early stages of infection and during the evolution of the chronic form $[7,11,12]$. Medullar schistosomiasis, in turn, is one of the most frequent manifestations of CNS attack by this parasitosis; it involves several presentations with inflammatory characteristics, including meningomyeloradicular, medullar, purely radicular, and pseudotumoral $[2,12]$. Cerebral schistosomiasis is the least frequent; it can be classified into: (1) acute, presenting fever, cephalea, and psychic manifestations; (2) convulsive type with focal or generalized crises; and (3) pseudotumoral, with intracranium hypertension and neurological location signs [13]. Cerebral lesions are most commonly caused by Schistosoma japonicum, and seldomly by $S$. haematobium or $S$. mansoni [14]. In our patients, the image exams confirmed the diagnosis of an expansive lesion, but they did not inform the etiology, since they do not distinguish between an inflammatory and a neoplastic process. However, the MRI can be quite useful for topographical diagnostics and, as with the CT, can demonstrate intradural and intramedullar lesions [5,14].

Eggs of $S$. mansoni in the tissues may lead to obstructive processes, formation of granulomas and hyper-sensibility reactions [12]. These eggs may be released into the general circulation and embolize towards the liver, the lungs and other
Figure 6.

Figure 7.
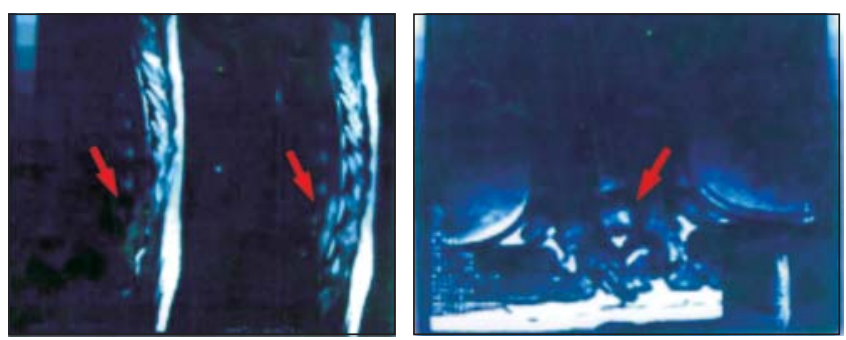

organs [12]. The most frequent ectopic manifestations may be found in the brain, in conjunctive tissues and in the spinal medulla [3]. However, perhaps due to the low inflammatory reactivity that the eggs provoke at a distance, the compromising of the CNS, associated with hepatosplenic and pulmonary forms, is generally non-symptomatic [11].

Epidemiologically, neuroschistosomiasis patients are predominantly males during their reproductive phase (predominantly from 20 to 50 years old) [12]. There is a predominance of low thoracic and lumbar involvement, fully coherent with the dissemination theory, along Batson's plexus [2]. Furthermore, granulomatous masses located in the more caudal portion of the spinal medulla and in the medullar cone are responsible for the symptoms in $78 \%$ of the cases. Pitella et al. (1981) reported that the eggs of S. mansoni in the brains of patients with the hepatosplenic disease form are largely found during necropsy, without finding the exact pathological meaning [15].

In most patients, sphincter disturbances precede the sensory and motor signs; in general, there is progressive compromise $[2,11,12]$. Sometimes, the meningeal syndrome is identified before medullar involvement is recognized, which could be due to an immunological reaction to the eggs. Generally, the interval between the assumed infection and the development of symptoms ranges from days to years.

The CSF analysis, in patients with medullar lesions, reveals general counts of cells varying from 10-300 leucocytes $/ \mathrm{mm}^{3}$, and can be normal during fast evolution periods. Differential cytology is characterized by lymphomonocyte sediment, in which eosinophils and plasmocytes predominate. The percentages of eosinophils in the CSF of patients with NS are variable and transitory, occurring more intensely in the initialinfection phase. NS is an important cause of clear and intense eosinophilorrhachia, characterizing eosinophilic meningitis. The protein concentration usually ranges from $50-150 \mathrm{mg} / \mathrm{dL}$. Glycorrhachia is usually normal or a bit low. Hypergammaglobulinemia occurs, according to literature reports, in more than half of the cases, which is coherent with the idea of inflammation provoking breach of the blood brain barrier [13] and is similar to what we found in our patients. The complement fixation reaction, as well as ELISA and immunofluorescence methods give good specificity and sensibility. The indirect hemagglutination reaction is more sensitive and less specific [12]. There has been little research 
on serology of patients with NS, while studies about antibodies in the CSF are even more limited. Santos et al. [16] found specific antibodies against the soluble egg antigen (SEA) and against the soluble worm adult preparation (SWAP) in the liquor of patients with clinical suspicion of NS, through ELISA, showing that different classes of immunoglobulins and isotypes can be detected. They found antibodies against SEA and SWAP in $97.6 \%$ of the cases.

Medullar schistosomiasis is manifested as four forms of anatomic pathology: (1) expansive granulomatous confluent intramedullar lesion; (2) radicular involvement, with granulomatous modifications of the medullar cone and equine cauda; (3) diffuse granulomatosis, with necrosis, atrophy and hemorrhage, causing an acute transverse myelitis, without medullar broadening; and (4) non-symptomatic egg deposition [8]. In our second patient, anatomic pathology of the lesion showed $S$. mansoni granuloma with necrotizing granulomatous reaction in the nervous tissue of the spinal medulla, with marked presence of eosinophils (Figures 8, 9 and 10).

Mattosinho-França et al. reported that dissemination of parasite eggs across the small-caliber brain arteries can cause intense necrosis, following by intra-parenchymatous hemorrhage, multiple cerebral hemorrhagic softening and schistosomiasis granulomas [17].

No NS treatment scheme has been definitely established [18]; it requires therapeutic consensus. Specific treatment of schistosomiasis can only be justified when there is active disease. As there are several factors involved, however, in CNS schistosomiasis pathogeny, we believe that the treatment of all NS patients is justified, unless the subgroups benefited by the therapy have not yet been confirmed. Regression of the medulla picture has been observed in patients treated with praziquantel or oxamniquine for three days, plus corticoids for a long period, ranging from one to two years duration $[2,3,11]$.

Surgical treatment of the granulomatous forms does not always result in complete extirpation of the lesion, since, in general, there is no well-defined cleavage plan, and it is difficult to differentiate inflamed tissue from normal medullar tissue. Furthermore, no advantage of the surgical, over clinical procedures has been demonstrated till now.

\section{References}

1. WHO - World Health Organization. The control of Schistosomiasis. Second report of WHO expert committee. Technical Report Geneva, Switzerland. Series 830, p. 86, 1993.

2. Andrade A.N. Neuroesquistossomose. Arq Neuropsiq $1986 ; 44: 275-9$

3. Andrade A.N., Bastos C.L. Esquistossomose mansônica cerebral. Arq Neuropsiq 1989;47:100-4.

4. Liu L.X., Compton C.C. A 40 year-old woman with rapid onset of flaccid paraplegia. N Engl J Med 1996;334:382-9.

5. Andrade Filho A.S., Queiroz A.C., Reis M.G., et al. In Clinica Neurológica. Cap 16, Neuroesquistossomose mansônica.Lemos, São Paulo, 1998, 111-20.

6. Masson C. Schistosomiasis médullaire: Apport de l'imagerie par résonance magnétique. La Presse Médicale $1990 ; 19(26): 1223-4$.

7. Andrade Filho A.S., Reis M.G., Souza A.1., et al. Neuroesquistossomose mansônica - Aspectos clínicos, laboratoriais e terapêuticos. Arq. Neuropsiq 1996;54(2):232-7.

8. Brito E., Santoro F., Rocha H., et al. Immune complexes in schistosomiasis. VI-Circulating IC levels in patients with and without nephropathy. Rev Inst Med Trop Sao Paulo 1979;21:119-24.

9. Bout D. Circulating immune complexes in Schistosomiasis. Immunology 1977;33:17-22.

10. Queiroz A.C. Estudo do Plexo Coróide na Esquistossomose Mansônica. Relação dos depósitos protéicos com glomerulonefrite associada. Acta Med Port 1984;5:219-21.

11. Andrade Filho A.S., Queiroz A.C. Meningomielorradiculite esquistossomótica. Estudo Clínico-Laboratorial de três casos relatados. Arq Neuropsiq 1991;49:80-2.

12. Gama C., Marques de Sá J. Esquistossomose medular. Granulomas produzidas por ovos do Schistosoma mansoni comprimindo a medula, epicone, cone e cauda equina. Arq Neuropsiq $1945 ; 3: 334-7$

13. Remencius A. Eosinophils in neuroschistosomiasis. Rev Brás Neurol 2001;37(1):19-23.

14. Scully, R.E. et al. Case records of the Massachusetts general hospital. New Engl J Med 2001;126-31.

15. Pitella J.E.H., Peixoto M.A.L. Brain involvement in hepatoesplenic schistosomiasis mansoni. Brain 1981;631-6.

16. Santos I.F.M., Lemaire D.C., Andrade Filho A.S., ET AL. Antibodies to Schistosoma mansoni in human cerebrospinal fluid. Am J Trop Med Hig 2003;68:294-8.

17. Mattosinho-França L.C., Melaragno R., Tenuto R.A. Comprometimento cerebral na esquistossomose mansônica. Rev. Paulista Méd 1965;67:224-9.

18. Nobre V., Silva L.C.S., Ribas J.G., et al. Schistosomal myeloradieculopathy due to Schitosoma mansoni: report on 23 cases. Mem Inst Oswaldo Cruz 2001;96:137-41.
Figure 8.

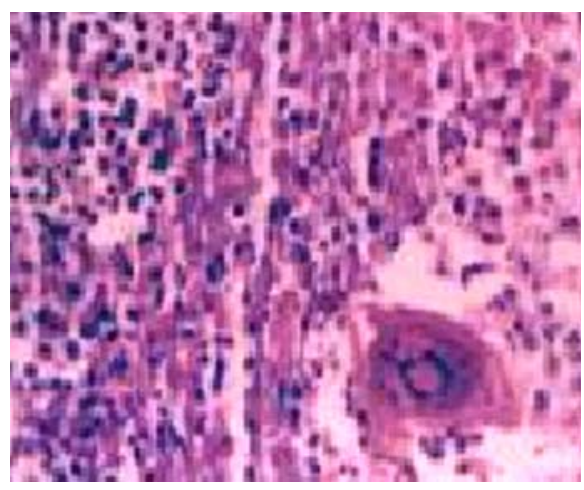

Figure 9.

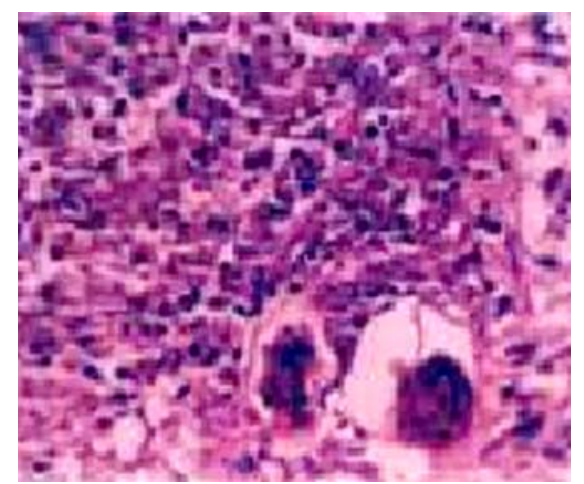

Figure 10.

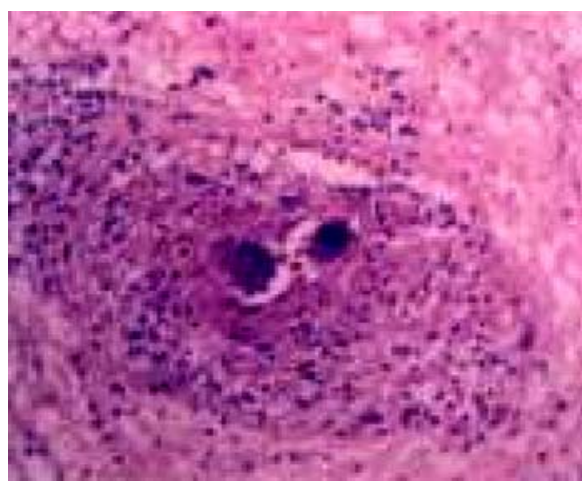

